\title{
Financial Implications of Early Hospital Discharge After AML-Like Induction Chemotherapy: A 4-Year Retrospective Analysis
}

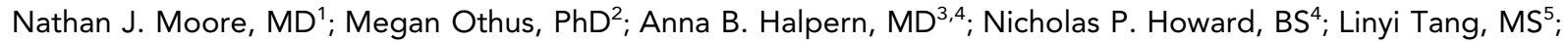 \\ Kyle E. Bastys, MPH'; Mary-Elizabeth M. Percival, MD, MS ${ }^{3,4}$; Paul C. Hendrie, MD, PhD ${ }^{3,5}$; Garrett A. Hartley, MBA, MPH'; \\ Verna L. Welch, PhD, $\mathrm{MPH}^{6}$; Elihu H. Estey, $\mathrm{MD}^{3,4}$; and Roland B. Walter, MD, PhD, MS $3,4,7,8$
}

\begin{abstract}
Background: Early hospital discharge (EHD) after intensive acute myeloid leukemia (AML) induction chemotherapy has become routine at the University of Washington/Seattle Cancer Care Alliance over the past several years. We assessed the financial implications of EHD over the first 4 years after its broad adoption for patients with AML and other high-grade myeloid neoplasms undergoing AML-like induction chemotherapy. Patients and Methods: We retrospectively compared charges between 189 patients with EHD who received all postinduction inpatient/outpatient care within our care system between August 2014 and July 2018 and 139 medically matched control patients who remained hospitalized for logistical reasons. Charges from the day of initial discharge (patients with EHD) or end of chemotherapy (control patients) until blood count recovery, additional chemotherapy or care transition, hospital discharge (for control patients only), an elapse of 42 days, or death were extracted from financial databases and separated into categories: facility/provider, emergency department, transfusions, laboratory, imaging, pharmacy, and miscellaneous. Results: Combined charges averaged $\$ 4,157 /$ day (range, $\$ 905-\$ 13,119 /$ day) for patients with EHD versus $\$ 9,248 /$ day (range, $\$ 4,363-\$ 48,522 /$ day) for control patients $(P<.001)$. The EHD cohort had lower mean facility/provider, transfusion, laboratory, and pharmacy charges but not imaging or miscellaneous charges. During readmissions, there was no statistically significant difference in daily inpatient charges between the EHD and control cohorts. After multivariable adjustment, average charges were $\$ 3,837 /$ day lower for patients with EHD $(P<.001)$. Conclusions: Together with previous data from our center showing that EHD is safe and associated with reduced healthcare resource utilization, this study further supports this care approach for AML and other high-grade myeloid neoplasms if infrastructure is available to enable close outpatient follow-up.
\end{abstract}

J Natl Compr Canc Netw, doi: 10.6004/jnccn.2020.7683 Published online June 22, 2021

${ }^{1}$ Department of Medicine, Residency Program, University of Washington, ${ }^{2}$ Public Health Sciences Division, Fred Hutchinson Cancer Research Center,

${ }^{3}$ Department of Medicine, Division of Hematology, University of Washington,

${ }^{4}$ Clinical Research Division, Fred Hutchinson Cancer Research Center, and

${ }^{5}$ Seattle Cancer Care Alliance, Seattle, Washington; ${ }^{6}$ Pfizer Inc., New York,

New York; and ${ }^{7}$ Department of Laboratory Medicine and Pathology, and

${ }^{8}$ Department of Epidemiology, University of Washington, Seattle, Washington.

\section{Background}

Adults with acute myeloid leukemia (AML) or other highgrade myeloid neoplasms typically remain hospitalized during the several weeks of profound pancytopenia after intensive induction chemotherapy. However, the need for hospitalization to permit the close monitoring and supportive care necessitated during such pancytopenia can be questioned by advancements in outpatient care and by the awareness of quality-of-life impairments during prolonged hospitalizations. ${ }^{1,2}$ At our institution, we have implemented a routine outpatient care strategy of early hospital discharge (EHD), operationally defined as initial hospital discharge within 72 hours of completing chemotherapy, based on results from a pilot and a phase II study conducted by group. ${ }^{3,4}$ In those studies, stringent medical and logistical criteria were used to establish EHD eligibility. Subsequently, EHD has been applied to a broader patient population not necessarily meeting these criteria. We recently reported our experience with this practice over a 4-year period since completing the phase II trial. ${ }^{5}$ Based on our analyses, EHD appeared safe, allowed patients to spend $>70 \%$ of their time until blood count recovery as outpatients, and was associated with fewer red blood cell and platelet transfusions. ${ }^{5}$

EHD may substantially reduce the cost of treating AML given studies identifying prolonged hospitalization as the major cost contributor. ${ }^{6,7}$ In our pilot study, ${ }^{3}$ median daily charges for patients with EHD were $>\$ 2,000$ lower ( $\$ 3,270$ vs $\$ 5,467)$ than for control patients with similar posttreatment courses. Results were similar in our follow-up phase II study (daily charges of $\$ 3,840$ vs $\$ 5,852) .{ }^{4}$ Both studies were limited by the relatively small number of inpatients who were control patients, reflecting restrictive study inclusion criteria. In this report we

See JNCCN.org for supplemental online content. 
have assessed the financial implications of EHD over the first 4 years after its broad adoption.

\section{Patients and Methods}

\section{Study Cohort}

We previously identified 375 adults with AML (except acute promyelocytic leukemia) or other high-grade myeloid neoplasm ( $\geq 10 \%$ blasts in blood and/or marrow) who received an initial course of intensive AML-like induction chemotherapy with $7+3$ or another regimen between August 1, 2014, and July 31, 2018. ${ }^{5}$ Hospital discharge immediately following completion of such therapies was routinely considered during this time period for all patients regardless of disease risk and specifics of the chemotherapy administered and independent of participation in a clinical trial, provided the patients were considered medically stable, had a caregiver, and had local lodging available (for those who did not use patient housing affiliated with our institution, commutes to the clinic were typically $\leq 1$ hour). For this analysis, patients were allocated to the EHD group if they were discharged within 72 hours of completing chemotherapy, as per our previous studies. ${ }^{3-5}$ Patients who remained hospitalized for logistical or medical reasons were considered control patients. Due to the inability to access financial charges from outside healthcare systems and compare them with similar data from our center, patients with EHD who had any outpatient follow-up or hospital readmissions at an out-of-system institution were excluded.

\section{Supportive Care}

All patients, regardless of discharge disposition, routinely received triple antimicrobial prophylaxis with acyclovir, an antibiotic (most typically levofloxacin), and an azole as per institutional practice. For outpatient care, patients came to the clinic 3 times/week for laboratory monitoring and transfusions. They were typically seen by a nurse for 2 of these visits and either a nurse practitioner or physician assistant for 1 weekly visit and when new problems arose. The physician typically saw them 1 to 2 times per cycle. All patients with neutropenic fever were admitted for intravenous antibiotics and evaluation. However, some patients were discharged to complete a course of intravenous antibiotics after they defervesced, provided they were clinically stable.

\section{Definition of Study Period}

As noted previously, ${ }^{5}$ the study ("at risk") period started with initial hospital discharge (for EHD patients) or completion of chemotherapy (for control patients). Any inpatient charges related to induction chemotherapy were excluded. The study period ended with the earliest of the following: recovery of absolute neutrophil count $\geq 500 / \mu \mathrm{L}$ and transfusion-independent platelet count of $\geq 20,000$ / $\mu \mathrm{L}$, hospital discharge (control patients only), receipt of additional AML-directed chemotherapy, transition to comfort care, initiation of pretransplant workup, after 42 days had elapsed, or death..$^{3-5}$

\section{Data Collection}

Baseline demographic and clinical information was recorded, including age, insurance type, and disease characteristics. The treatment-related mortality (TRM) score was computed with an online calculator (https://cstaging. fhcrc-research.org/TRM/) as previously described. ${ }^{8}$ To obtain data on charges, medical record numbers and study period were provided to clinical analysts, and institutional databases of financial charges were queried. Output data included all individual charges associated with the patient within the defined study period. Additional data provided for each charge included patient class (inpatient vs outpatient charge), current procedural terminology code, cost center name/code, date of service, encounter discharge date, ordering provider, and billing provider.

\section{Charge Categorization}

Charges were broken down into inpatient and outpatient charges and further categorized as follows: (1) hospital/provider charges, including all hospital bed charges, procedures including blood draws, biopsies, bronchoscopies, and outpatient provider fees; (2) emergency department charges; (3) transfusion-related charges attached to blood products, infusion procedural charges, and all laboratory studies related to transfusions including blood typing; (4) laboratory charges, including all non-transfusion-related laboratory studies such as blood counts, basic metabolic panels, and lung function tests; microbiology including blood, sputum, and urine cultures; and pathology including tissue microscopy, flow cytometry, and associated genomic studies; (5) imaging charges, including all radiographs, CT scans, MRIs, and ultrasound studies (eg, echocardiograms, abdominal ultrasound, venous duplex studies); (6) pharmacy charges, including all medications and associated administration charges; and (7) a miscellaneous category, which captured ancillary services provided to inpatients and outpatients and predominantly included physical therapy, occupational therapy, and respiratory therapy.

\section{Outcomes of Interest}

Primary outcomes of interest were total charges per study day and charges per inpatient study day. For the EHD group, we also recorded charges per outpatient study day. Secondary outcomes of interest included per study day charges of each charge category.

\section{Statistical Analysis}

Fisher exact and Kruskal-Wallis tests were used to assess differences between categorical and quantitative variables 
across categories, as appropriate. Multivariable linear regression models were used to assess the relationship between covariates and outcomes of interest. Outcome analyses accounted for days on study. Two-sided $P$ values were reported. Statistical analyses were performed using R (http://www.r-project.org).

\section{Results}

Study Population

Of the 375 adults receiving a first course of induction chemotherapy between August 1, 2014, and July 31, 2018,236 were discharged within 72 hours of completing chemotherapy (the EHD group). ${ }^{5}$ Of these 236 patients, 189 received all outpatient and inpatient care at clinics and hospitals within our institution during the designated study period and were included in this analysis. A total of 139 patients remained hospitalized for logistical or medical reasons and served as standard care (inpatient) controls. As summarized in Tables 1 and 2, EHD and control patients were similar in terms of age, sex, disease characteristics, and insurance type. They differed, however, with regard to prechemotherapy and postchemotherapy performance status and TRM score (better in EHD patients), type of induction chemotherapy given, distance from permanent or temporary residence to outpatient clinic (closer for EHD patients), reason to come off the study (most commonly, count recovery for EHD patients vs hospital discharge for control patients), and response to chemotherapy (higher rates of complete remission [CR] and complete remission with incomplete hematologic recovery [CRi] or the EHD group).

\section{Overview of Charge Distribution}

For EHD patients, facility/provider charges accounted for $32 \%$ of total charges, $29 \%$ of transfusion-related charges,

\section{Table 1. Cohort Characteristics}

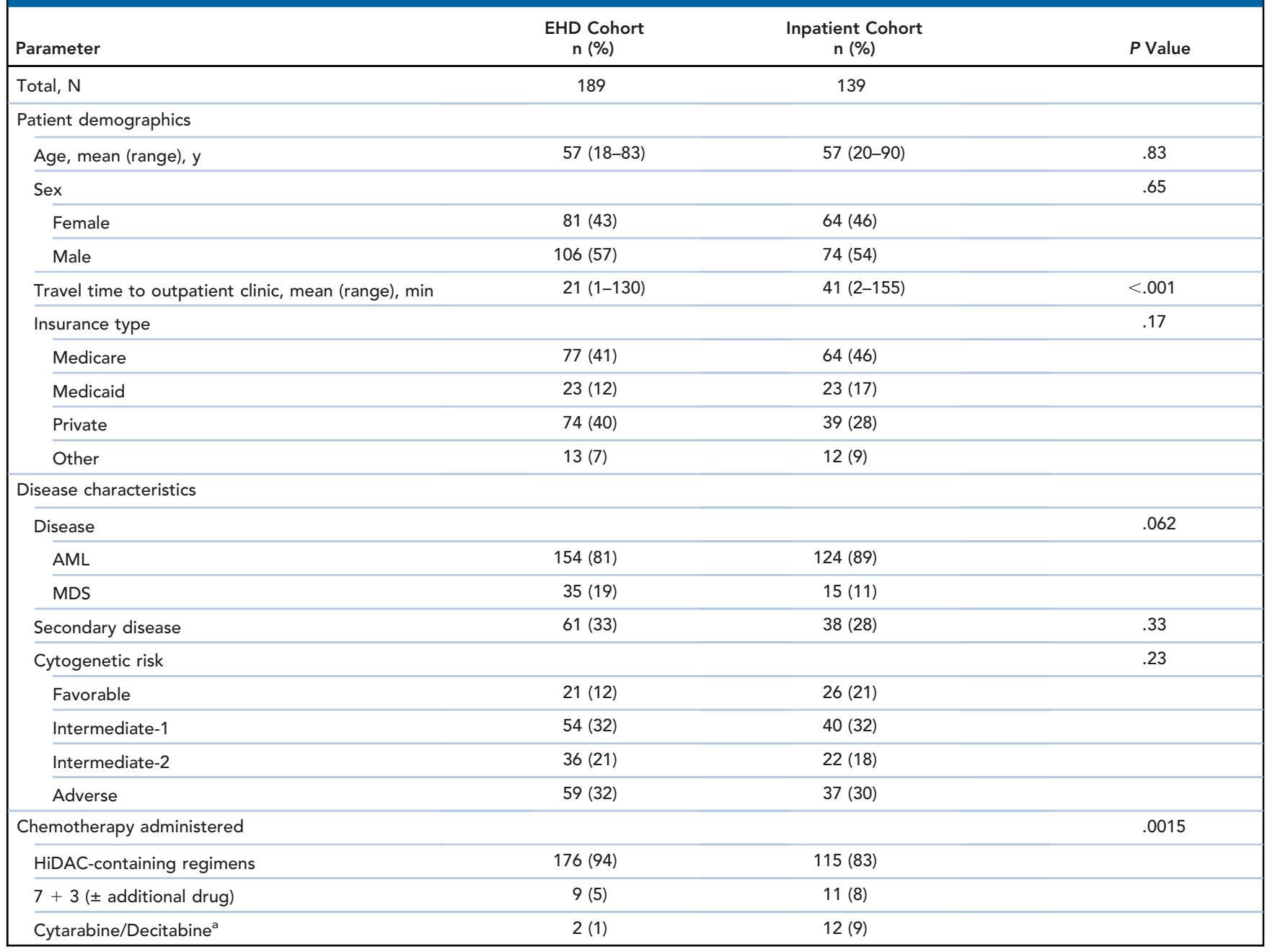




\begin{tabular}{|c|c|c|c|}
\hline Parameter & $\begin{array}{l}\text { EHD Cohort } \\
\text { n (\%) }\end{array}$ & $\begin{array}{c}\text { Inpatient Cohort } \\
\mathrm{n}(\%)\end{array}$ & $P$ Value \\
\hline \multicolumn{4}{|l|}{ Clinical/Laboratory findings at baseline } \\
\hline Performance status & & & $<.001$ \\
\hline $0-1$ & $157(84)$ & $93(67)$ & \\
\hline $2-4$ & $30(16)$ & $45(33)$ & \\
\hline Creatinine, $\mathrm{mg} / \mathrm{dL}$ & $0.92(0.39-4.36)$ & $0.96(0.34-3.36)$ & .22 \\
\hline Total bilirubin, $\mathrm{mg} / \mathrm{dL}$ & $0.84(0.2-7.7)$ & $0.73(0.2-3.0)$ & .5 \\
\hline Albumin, g/dL & $3.84(2.3-5.0)$ & $3.48(2.2-4.9)$ & $<.001$ \\
\hline WBC count, thousand/microL & $20.39(0.39-261.48)$ & $33.82(0.29-247.93)$ & .0021 \\
\hline$\%$ peripheral blood blasts & $24.63(0-97)$ & $33.53(0-97)$ & .0037 \\
\hline TRM score & $4.61(0-37.74)$ & $9.85(0-45.20)$ & $<.001$ \\
\hline \multicolumn{4}{|c|}{ Clinical/Laboratory findings postchemotherapy } \\
\hline Performance status & & & $<.001$ \\
\hline $0-1$ & $160(86)$ & $71(51)$ & \\
\hline $2-4$ & $27(14)$ & $67(49)$ & \\
\hline Creatinine, $\mathrm{mg} / \mathrm{dL}$ & $0.72(0.32-2.65)$ & $0.82(0.21-2.71)$ & .021 \\
\hline Total bilirubin, mg/dL & $0.99(0.2-5.1)$ & $1.12(0.2-9.4)$ & .46 \\
\hline Albumin, g/dL & $3.50(2.1-5.0)$ & $3.12(1.8-4.6)$ & $<.001$ \\
\hline WBC count, thousand/microL & $1.11(0-37.20)$ & $0.68(0-14.73)$ & .12 \\
\hline$\%$ peripheral blood blasts & $1.28(0-46)$ & $1.88(0-69)$ & .94 \\
\hline TRM score & $6.92(0.34-48.44)$ & $14.45(0.11-78.63)$ & $<.001$ \\
\hline Treatment response & & & $<.001$ \\
\hline No CR/CRi & $38(20)$ & $54(39)$ & \\
\hline CR or $\mathrm{CRi}$ & $151(80)$ & $85(61)$ & \\
\hline Off-study reason & & & $<.001$ \\
\hline Blood count recovery & $153(82)$ & $41(30)$ & \\
\hline Day 42 & $13(7)$ & $2(1)$ & \\
\hline Death & $8(4)$ & $6(4)$ & \\
\hline Hospital discharge & $0(0)$ & $82(59)$ & \\
\hline New AML therapy & $9(5)$ & $7(5)$ & \\
\hline Transfer of care to outside facility & $4(2)$ & $0(0)$ & \\
\hline
\end{tabular}

Abbreviations: $A M L$, acute myeloid leukemia; $C R$, complete remission; $C R i$, complete remission with incomplete hematologic recovery; EHD, early hospital discharge; HiDAC, high-dose cytarabine; MDS, myelodysplastic syndromes; TRM, treatment-related mortality; WBC, white blood cell.

${ }^{a}$ Cytarabine, $100 \mathrm{mg} / \mathrm{m}^{2} \times 7$ days, and decitabine, $20 \mathrm{mg} / \mathrm{m}^{2} \times 10$ days.

$17 \%$ of laboratory/pathology charges, and $14 \%$ of pharmacy charges, and imaging, miscellaneous, and emergency department charges constituted only $5 \%, 2 \%$, and $2 \%$ of total charges, respectively. The distribution of applicable charges was similar for control patients although it weighed more heavily toward facility/provider charges $(40 \%)$ and pharmacy charges (18\%). Transfusion-related charges $(25 \%)$ and laboratory/pathology charges $(10 \%)$ constituted smaller fractions compared with EHD patients. Similarly, imaging and miscellaneous charges contributed small fractions at $4 \%$ and $2 \%$, respectively.

\section{Comparison of Charges Between EHD and} Control Patients

EHD was associated with significantly lower combined inpatient and outpatient charges when compared with continued hospitalization (Table 3). Specifically, EHD patients had combined mean charges of $\$ 4,157 /$ day (range, \$905-\$13,119/day), whereas charges among control patients averaged $\$ 9,248 /$ day (range, $\$ 4,363-\$ 48,522$ / day; $P<.001$ ). These differences reflected differences in several subcategories of charges, including facility/provider charges ( $\$ 1,312$ vs $\$ 3,687 /$ day; $P<.001)$, transfusion charges $(\$ 1,205$ vs $\$ 2,331 /$ day; $P<.001)$, laboratory/ 


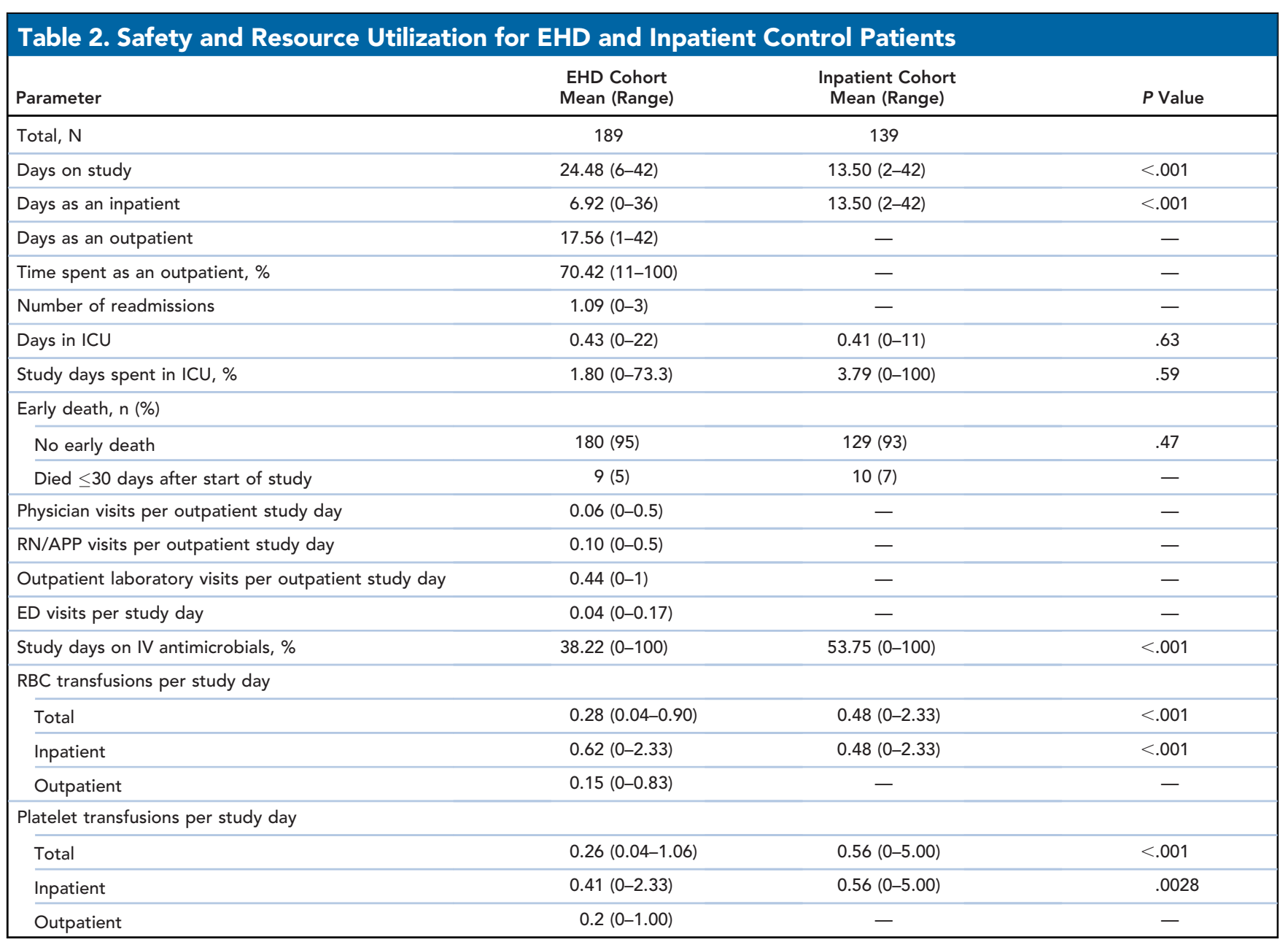

Abbreviations: APP, advanced practice provider; ED, emergency department; EHD, early hospital discharge; ICU, intensive care unit; IV, intravenous; $\mathrm{RBC}$, red blood cell; RN, registered nurse.

pathology charges ( $\$ 707$ vs $\$ 961 /$ day; $P<.001$ ), and pharmacy charges ( $\$ 563$ vs $\$ 1,701 /$ day; $P<.001$ ). In contrast, there was no difference between imaging charges ( $\$ 209$ vs $\$ 372 /$ day; $P=.34$ ) or miscellaneous charges ( $\$ 90$ vs $\$ 197 /$ day; $P=.33$ ).

Of the 189 EHD patients, 154 (81\%) were readmitted at least once. During rehospitalizations, daily inpatient charges for EHD patients were similar to those of control patients: \$8,468/inpatient day (range, $\$ 4,828-\$ 19,605 /$ inpatient day) versus $\$ 9,248 /$ day (range, $\$ 4,363-\$ 48,522 /$ day; $P=.35$; Table 3 ). After readmission, there were no differences between the EHD and control groups regarding inpatient facility/ provider charges $(\$ 3,487$ /inpatient day vs $\$ 3,687 /$ inpatient day; $P=.87)$ or pharmacy charges $(\$ 1,589$ vs $\$ 1,701 /$ inpatient day; $P=.98$ ). EHD patients incurred fewer inpatient transfusion-related charges $(\$ 1,758$ vs $\$ 2,331 /$ inpatient day; $P<.001$ ) and miscellaneous charges ( $\$ 120$ vs $\$ 197 /$ inpatient day; $P<.001)$ relative to control patients. In contrast, inpatient laboratory and imaging charges were higher for patients with EHD during rehospitalizations than for control patients, with average inpatient laboratory charges of $\$ 1,045 /$ inpatient day for EHD patients versus $\$ 961 /$ inpatient day for control patients $(P=.037)$ and average inpatient imaging charges of $\$ 552$ /inpatient day for EHD patients versus $\$ 372 /$ inpatient day for control patients $(P<.001)$.

Among the 189 EHD patients, outpatient charges averaged \$2,305 per outpatient study day (range, $\$ 0-\$ 7,450 /$ day). As summarized in Table 4, facility/provider charges averaged $\$ 350 /$ day (range, $\$ 0-\$ 1,426 /$ day), emergency department charges were $\$ 207 /$ day (range, $\$ 0-\$ 2,858 /$ day), transfusion charges averaged $\$ 971 /$ day (range, \$0-\$4,674/day), laboratory/pathology charges averaged \$569/day (range, \$0-\$4,633/day), imaging charges averaged $\$ 38 /$ day (range, $\$ 0-\$ 631 /$ day), pharmacy charges averaged $\$ 105 /$ day (range, $\$ 0-\$ 1,405 /$ day), and miscellaneous charges averaged \$66/day (range, $\$ 0-\$ 273 /$ day). Notably, EHD patients who were 
Table 3. Charges per Day for EHD and Inpatient Control Patients

\begin{tabular}{|c|c|c|c|}
\hline Charge Category & $\begin{array}{c}\text { EHD Cohort } \\
\text { Charges per Day (Range), USD }\end{array}$ & $\begin{array}{c}\text { Inpatient Cohort } \\
\text { Charges per Day (Range), USD }\end{array}$ & $P$ Value \\
\hline Total, N & $189 ; 154$ for inpatient only & 139 & \\
\hline Combined & $4,157(905-13,119)$ & $9,248(4,363-48,522)$ & $<.001$ \\
\hline Inpatient only & $8,468(4,828-19,605)$ & $9,248(4,363-48,522)$ & .35 \\
\hline Inpatient only & $3,487(1,588-8,571)$ & $3,687(2,806-19,610)$ & .87 \\
\hline \multicolumn{4}{|c|}{ Emergency department } \\
\hline Combined & $102(0-480)$ & $0(0-0)$ & $<.001$ \\
\hline \multicolumn{4}{|l|}{ Transfusion } \\
\hline Combined & $707(87-2,398)$ & $961(130-4,624)$ & $<.001$ \\
\hline Inpatient only & $1,045(299-2,896)$ & $961(130-4,624)$ & .037 \\
\hline \multicolumn{4}{|l|}{ Imaging } \\
\hline Combined & $209(0-1,761)$ & $372(0-5,151)$ & .34 \\
\hline Inpatient only & $552(0-2,904)$ & $372(0-5,151)$ & $<.001$ \\
\hline \multicolumn{4}{|l|}{ Pharmacy } \\
\hline Combined & $563(10-3,170)$ & $1,701(130-5,454)$ & $<.001$ \\
\hline Inpatient only & $1,589(265-3,731)$ & $1,701(130-5,454)$ & .98 \\
\hline \multicolumn{4}{|l|}{ Miscellaneous } \\
\hline
\end{tabular}

Abbreviation: EHD, early hospital discharge.

readmitted during their study periods $(n=154)$ had slightly higher outpatient charges ( $\$ 2,394 /$ outpatient day) than those who did not require readmission $(\$ 1,912$ /outpatient day).

We then conducted a multivariable linear regression analysis including care strategy (EHD vs continued inpatient care), age, sex, disease type (AML vs myelodysplastic syndrome), secondary disease (yes vs no), chemotherapy regimen, performance status, postchemotherapy TRM score, meeting strict medical and logistic criteria for inclusion in prior prospective studies, ${ }^{3,4}$ and insurance type (private vs Medicare vs Medicaid). As illustrated in Table 5, when controlling for these variables, we found that continued inpatient care postinduction chemotherapy was associated with an increase in charges per study day of $\$ 3,837$ relative to EHD care $(P<.001)$ among all patients. Postchemotherapy TRM and private insurance (relative to Medicare) were also predictive of higher per-day charges $(\$ 158 /$ day $\quad[P<.001]$ and $\$ 1,253 /$ day $[P=.009]$, respectively).
We considered the possibility that hospital discharge for control patients before the time of blood count recovery could impact the average daily charge estimates for the control cohort. We therefore conducted a subset analysis restricting the dataset to patients with $\mathrm{EHD}$ and control

\begin{tabular}{|c|c|}
\hline Charge Category & $\begin{array}{c}\text { EHD Cohort } \\
\text { Cost per Outpatient Day (Range), USD }\end{array}$ \\
\hline All categories & $2,305(0-7,450)$ \\
\hline Facility/Provider & $350(0-1,427)$ \\
\hline Emergency department & $207(0-2,858)$ \\
\hline Transfusion & $971(0-4,674)$ \\
\hline Laboratory/Pathology & $569(0-4,633)$ \\
\hline Imaging & $38(0-631)$ \\
\hline Pharmacy & $105(0-1,405)$ \\
\hline Miscellaneous & $66(0-273)$ \\
\hline
\end{tabular}




\begin{tabular}{|c|c|c|c|}
\hline Variable & Coefficient & $95 \% \mathrm{Cl}$ & $P$ Value \\
\hline Inpatient control patients (vs those with EHD) & 3,875 & 3,043 to 4,707 & $<.001$ \\
\hline Age & -20 & -52 to 12 & .21 \\
\hline Male (vs female) & -636 & $-1,371$ to 99 & .091 \\
\hline AML (vs MDS) & 122 & 905 to 1,148 & .82 \\
\hline Secondary (vs de novo) & 451 & -356 to 1,258 & .27 \\
\hline \multicolumn{4}{|l|}{ Chemotherapy regimen } \\
\hline HiDAC-containing regimen (vs $7+3 \pm$ drug) & 366 & $-1,147$ to 1,879 & .64 \\
\hline \multicolumn{4}{|l|}{ Insurance type } \\
\hline Medicaid (vs Medicare) & 501 & -822 to 1,824 & .46 \\
\hline Private (vs Medicare) & 1,220 & 280 to 2,160 & .011 \\
\hline Other (vs Medicare) & 754 & -778 to 2,285 & .34 \\
\hline
\end{tabular}

Abbreviations: AML, acute myeloid leukemia; EHD, early hospital discharge; HiDAC, high-dose cytarabine; MDS, myelodysplastic syndromes; TRM, treatmentrelated mortality.

patients who came off-study because of blood count recovery. The characteristics of the 153 patients with EHD and 41 control patients meeting this criterion are presented in supplemental eTables 1 and 2 (available with this article at JNCCN.org). As summarized in supplemental eTable 3, the comparisons of the daily charges for this EHD group and control patient subset were very similar to the comparisons in the entire dataset, again showing significantly lower per-day charges for EHD versus control patients $(\$ 3,826$ vs $\$ 8,404 /$ day; $P<.001)$.

\section{Medically Matched Patients With EHD Versus Control Patients}

To address the possibility that clinical characteristics, including disease severity, influenced financial analyses, we conducted a subset analysis restricting our dataset to medically matched EHD and control patients. In our earlier pilot and phase II studies, patients included met an explicit list of medical criteria for inclusion. ${ }^{3,4}$ In the present study, we identified 152 of 189 EHD patients and 49 of 139 control patients who met these criteria. These 2 cohorts of medically matched patients had a similar baseline performance status and TRM score but differed regarding treatment response (higher $\mathrm{CR} / \mathrm{CRi}$ rates among EHD patients) and distance to outpatient clinic (closer for EHD patients; supplemental eTables 4 and 5).

As shown in Table 6, EHD patients who met strict medical EHD criteria had lower per-day charges than matched control patients ( $\$ 3,929$ vs $\$ 7,306 /$ day; $P<.001$ ), similar to findings for the entire cohort. This was also true for facility/provider charges $(\$ 1,234$ vs $\$ 3,320 /$ day; $P<.001)$, transfusion charges $(\$ 1,142$ vs $\$ 1,736 /$ day; $P<.001$ ), and pharmacy charges ( $\$ 522$ vs $\$ 1,233 /$ day; $P<.001)$. There was no difference between laboratory/ pathology charges ( $\$ 692$ vs $\$ 780 /$ day; $P=.19$ ) or imaging charges ( $\$ 181$ vs $\$ 167 /$ day; $P=.057$ ). However, patients with EHD had higher miscellaneous charges than medically matched control patients ( $\$ 84$ vs $\$ 70 /$ day; $P<.001$ ).

We also compared inpatient per-day charges for medically matched EHD and control patients (Table 6). Within this subset of patients, inpatient per-day charges were higher for patients with EHD compared with control patients ( $\$ 8,262$ vs $\$ 7,306 /$ day; $P=.0086)$. Among the subcategories analyzed, there was no difference between facility/provider charges ( $\$ 3,453$ vs $\$ 3,320 /$ day; $P=.56$ ), transfusion-related charges ( $\$ 1,653$ vs $\$ 1,736 /$ day; $P=.88$ ), and miscellaneous charges ( $\$ 106$ vs $\$ 70 /$ day; $P=.80$ ). Rather, higher inpatient costs for medically matched EHD patients seemed to be driven by higher laboratory/pathology ( $\$ 1,038$ vs $\$ 780 /$ day; $P=.0012$ ), imaging ( $\$ 547$ vs $\$ 167 /$ day; $P<.001)$, and pharmacy charges $(\$ 1,550$ vs $\$ 1,233 /$ day; $P<.001$ ).

Multivariable linear regression analysis for the medically matched patient subset revealed results similar to those of the entire cohort (Table 7). Continued inpatient care was associated with a $\$ 3,476$ increase in per-day 


\begin{tabular}{|c|c|c|c|}
\hline Charge Category & $\begin{array}{c}\text { EHD Cohort } \\
\text { Charges per Day (Range), USD }\end{array}$ & $\begin{array}{l}\text { Inpatient Cohort } \\
\text { Charges per Day (Range), USD }\end{array}$ & $P$ Value \\
\hline \multicolumn{4}{|l|}{ All categories } \\
\hline Combined & $3,929(905-12,025)$ & $7,306(4,363-11,881)$ & $<.001$ \\
\hline Inpatient only & $8,262(4,828-19,605)$ & $7,306(4,363-11,881)$ & .0086 \\
\hline \multicolumn{4}{|l|}{ Facility/Provider } \\
\hline Combined & $1,234(104-4,723)$ & $3,320(3,034-4,594)$ & $<.001$ \\
\hline Inpatient only & $3,453(1,588-8,571)$ & $3,320(3,034-4,594)$ & .56 \\
\hline \multicolumn{4}{|c|}{ Emergency department } \\
\hline Combined & $102(0-480)$ & $0(0-0)$ & $<.001$ \\
\hline \multicolumn{4}{|l|}{ Transfusion } \\
\hline Combined & $1,142(225-3,780)$ & $1,736(518-5,247)$ & $<.001$ \\
\hline Inpatient only & $1,653(306-3,898)$ & $1,736(518-5,247)$ & .88 \\
\hline \multicolumn{4}{|c|}{ Laboratory/Pathology } \\
\hline Combined & $692(87-2,398)$ & $780(130-4,624)$ & .19 \\
\hline Inpatient only & $1,038(299-2,896)$ & $780(130-4,624)$ & .0012 \\
\hline \multicolumn{4}{|l|}{ Imaging } \\
\hline Combined & $181(0-920)$ & $167(0-1,272)$ & .057 \\
\hline Inpatient only & $547(0-2,904)$ & $167(0-1,272)$ & $<.001$ \\
\hline \multicolumn{4}{|l|}{ Pharmacy } \\
\hline Combined & $522(10-2,885)$ & $1,233(130-3,203)$ & $<.001$ \\
\hline Inpatient only & $1,550(265-3,731)$ & $1,233(130-3,203)$ & $<.001$ \\
\hline \multicolumn{4}{|l|}{ Miscellaneous } \\
\hline Combined & $84(0-1,012)$ & $70(0-775)$ & $<.001$ \\
\hline Inpatient only & $106(0-1,849)$ & $70(0-775)$ & .8 \\
\hline
\end{tabular}

Abbreviation: EHD, early hospital discharge.

charges compared with early discharge. Within this medically matched cohort, only secondary disease (relative to de novo disease) was also associated with higher charges per day $(\$ 744 ; P=.022)$.

Finally, we conducted a subset analysis of only those medically matched patients whose study period ended with blood count recovery, acknowledging the limitation of the small number of control patients in this subgroup. As shown in supplemental eTables 6 and 7, these 130 EHD patients and 15 control patients were similar regarding performance status, TRM score, and treatment response. In line with our other analyses, overall per-day charges for the EHD cohort were significantly lower than for the control cohort ( $\$ 3,792$ vs $\$ 6,429 /$ day; $P<.001$; supplemental eTable 8).

\section{Discussion}

The high costs associated with the treatment of AML and other high-grade hematologic malignancies have been widely documented. ${ }^{7,9-12}$ Our analyses suggest that EHD after intensive AML induction chemotherapy leads to substantial reductions in charges for postchemotherapy care compared with the standard approach of keeping patients in the hospital until recovery of peripheral blood counts.

Our findings are consistent with prior, smaller-scale examinations of the financial implications of EHD at our institution ${ }^{2-4}$ and elsewhere. ${ }^{13,14}$ For patients in our study, outpatient charges were approximately $\$ 6,000$ to $\$ 7,000$ per day less than inpatient charges. Lower provider/facility-related charges accounted for approximately half of the charge reduction, predominantly reflecting inpatient hospital bed charges and outpatient clinic fees, the latter of which were significantly lower. Our analysis also identifies cost reductions because of differences in blood product administration and other transfusion-related care in the inpatient versus outpatient setting. Although this difference may be related to the lower cost of care delivery in outpatient infusion centers, lower rates of blood product administration for EHD patients, perhaps because of less-frequent laboratory monitoring, may contribute as well. Notably, several analyses did not find frequent readmission for bleeding or complications of anemia in a prior safety evaluation of the EHD approach. ${ }^{5}$ Finally, lower pharmacy charges (mostly related 


\begin{tabular}{|c|c|c|c|}
\hline Variable & \multicolumn{2}{|c|}{ Charges per Day, USD } & $P$ Value \\
\hline Inpatient controls (vs patients with EHD) & 3,476 & 2,829 to 4,122 & $<.001$ \\
\hline Age & 27 & -2 to 57 & .068 \\
\hline \multicolumn{4}{|l|}{ Disease type } \\
\hline AML (vs MDS) & -227 & -985 to 531 & .56 \\
\hline Secondary (vs de novo) & 744 & 111 to 1378 & .022 \\
\hline \multicolumn{4}{|l|}{ Chemotherapy regimen } \\
\hline HiDAC-containing regimen (vs $7+3 \pm$ drug) & -795 & $-2,184$ to 594 & .26 \\
\hline Medicaid (vs Medicare) & 505 & -553 to 1,564 & .35 \\
\hline Private (vs Medicare) & 539 & -187 to 1,266 & .15 \\
\hline Other (vs Medicare) & 204 & -927 to 1,334 & .72 \\
\hline
\end{tabular}

Abbreviations: AML, acute myeloid leukemia; EHD, early hospital discharge; HiDAC, high-dose cytarabine; MDS, myelodysplastic syndromes; TRM, treatmentrelated mortality.

to medication administration) accounted for substantial differences between the 2 groups.

The charge reductions from shifting care to the outpatient setting were not negated by higher inpatient charges when EHD patients did require readmission. As noted in previous studies on $\mathrm{EHD}{ }^{3-5}$ readmission is common. In this analysis, 154 of the $189 \mathrm{EHD}$ patients (81\%) were readmitted at least once during the study period, for an average readmission rate of 1.1 per patient with EHD. Rehospitalization itself has been identified as an area of significant cost to the healthcare system. ${ }^{15}$ Thus, one could hypothesize that daily inpatient charges might be higher among EHD patients, as suggested in a previous phase II resource utilization analysis, ${ }^{4}$ perhaps related to the resource-intense readmission process or to the higher level of illness of rehospitalized patients. Consistent with this notion, among the cohort of medically matched patients, those with EHD who were readmitted did accumulate slightly higher inpatient charges. Laboratory and imaging charges were higher for readmitted EHD patients compared with control patients (both for all patients and for medically matched patients), perhaps because of extensive diagnostic evaluations performed upon hospital admission. However, EHD and control patients spent a similar gross number of days and percentage of study days in the ICU, further contributing to similar inpatient charge profiles. ICU admissions have been identified as a major contributor to inpatient medical costs in patients with hematologic malignancies, including AML. ${ }^{16,17}$
In the current analysis, we found the difference between charges incurred by EHD and control patients to be considerably larger than in prior studies. ${ }^{3,4,13,14}$ However, we caution against direct comparison with these data. First, to standardize our data, we used hospital and clinic charges in lieu of actual reimbursement, whether from an insurer or out of pocket. This approach avoided introducing payment discrepancies and inconsistencies within a heterogeneous insurer and payment landscape. ${ }^{4}$ In addition, we specifically excluded patients who received care within other healthcare systems to avoid potentially missing charges. Finally, healthcare charges and delivery practices evolve, making it difficult to compare temporally and spatially separated studies.

In addition to being a single-center, nonrandomized, and retrospective analysis, study limitations include our inability to account for costs to patients, their families, and the medical system that are not captured in electronic billing records. EHD patients likely bear more significant out-of-pocket expenses, of which prescription copays are the most notable, but also include transportation, lodging, and home healthcare. This study could also not account for financial and nonfinancial costs to caretakers, such as time taken away from work. Additionally, patients receiving care at outside healthcare systems were excluded from analysis to standardize charges. Furthermore, this study aimed to compare the financial implications of postinduction supportive care. It proved difficult to fully isolate nonsupportive charges (eg, those related to preparation of allogeneic hematopoietic cell 
transplantation), particularly during inpatient stays. Because of this difficulty, we included all charges in the final analysis. However, because pretransplant evaluations were more frequent in the EHD cohort, inclusion of such charges would bias our results toward a smaller difference in costs between EHD and standard inpatient care. Lastly, as mentioned before, we used charges rather than actual healthcare costs to enable interpatient comparisons.

\section{Conclusions}

Our study suggests that EHD after intensive AML induction chemotherapy is associated with reduced healthcare-related costs. Together with previous data from our institution showing that EHD is safe and associated with reduced healthcare resource utilization, ${ }^{3-5}$ this study further supports EHD for AML and other high-grade myeloid neoplasms if infrastructure is available ${ }^{18,19}$ to enable close outpatient follow-up.
Submitted August 27, 2020; accepted for publication November 3, 2020. Published online June 22, 2021.

Author contributions: Study concept and design: Moore, Halpern, Walter. Data acquisition: Moore, Halpern, Howard, Tang, Bastys. Statistical analysis: Othus. Analysis and interpretation of results: Moore, Othus, Halpern, Walter. Manuscript preparation: Moore, Othus, Halpern, Walter. Critical review and edit of final draft: All authors. Project supervision: Halpern, Walter.

Disclosures: Drs. Hartley and Welch have disclosed employment at and equity ownership in Pfizer. The remaining authors have disclosed that they have not received any financial consideration from any person or organization to support the preparation, analysis, results, or discussion of this article.

Disclaimer: R.B. Walter had full access to all of the data in this study and takes complete responsibility for the integrity of the data and the accuracy of the data analysis.

Funding: Research reported in this publication was supported by a sponsored research agreement with Pfizer, Inc., and a University of Washington Department of Medicine Quality and Safety Accelerator Grant (both to R.B. Walter).

Correspondence: Roland B. Walter, MD, PhD, MS, Clinical Research Division, Fred Hutchinson Cancer Research Center/University of Washington, 1100 Fairview Avenue North, D2-190, Seattle, WA 981091024. Email: rwalter@fredhutch.org

\section{References}

1. Vaughn JE, Buckley SA, Walter RB. Outpatient care of patients with acute myeloid leukemia: benefits, barriers, and future considerations. Leuk Res 2016;45:53-58.

2. Halpern $A B$, Walter RB, Estey $E H$. Outpatient induction and consolidation care strategies in acute myeloid leukemia. Curr Opin Hematol 2019;26: 65-70.

3. Walter RB, Lee SJ, Gardner KM, et al. Outpatient management following intensive induction chemotherapy for myelodysplastic syndromes and acute myeloid leukemia: a pilot study. Haematologica 2011;96:914-917.

4. Vaughn JE, Othus M, Powell MA, et al. Resource utilization and safety of outpatient management following intensive induction or salvage chemotherapy for acute myeloid leukemia or myelodysplastic syndrome: a nonrandomized clinical comparative analysis. JAMA Oncol 2015;1: 1120-1127.

5. Halpern AB, Howard NP, Othus $M$, et al. Early hospital discharge after intensive induction chemotherapy for adults with acute myeloid leukemia or other high-grade myeloid neoplasm. Leukemia 2020;34:635-639.

6. Redaelli A, Botteman MF, Stephens JM, et al. Economic burden of acute myeloid leukemia: a literature review. Cancer Treat Rev 2004;30: 237-247.

7. Meyers J, Yu Y, Kaye JA, et al. Medicare fee-for-service enrollees with primary acute myeloid leukemia: an analysis of treatment patterns, survival, and healthcare resource utilization and costs. Appl Health Econ Health Policy 2013;11:275-286.

8. Walter RB, Othus M, Borthakur G, et al. Prediction of early death after induction therapy for newly diagnosed acute myeloid leukemia with pretreatment risk scores: a novel paradigm for treatment assignment. J Clin Oncol 2011;29:4417-4423.

9. Preussler JM, Meyer CL, Mau LW, et al. Healthcare costs and utilization for patients age 50 to 64 years with acute myeloid leukemia treated with chemotherapy or with chemotherapy and allogeneic hematopoietic cell transplantation. Biol Blood Marrow Transplant 2017;23:1021-1028.
10. Stein EM, Bonifacio G, Latremouille-Viau D, et al. Treatment patterns, healthcare resource utilization, and costs in patients with acute myeloid leukemia in commercially insured and Medicare populations. J Med Econ 2018;21:556-563.

11. Hagiwara M, Sharma A, Chung KC, et al. Healthcare resource utilization and costs in patients with newly diagnosed acute myeloid leukemia. J Med Econ 2018:21:1119-1130.

12. Pandya BJ, Chen CC, Medeiros BC, et al. Economic and clinical burden of acute myeloid leukemia episodes of care in the United States: a retrospective analysis of a commercial payer database. J Manag Care Spec Pharm 2020;26:849-859.

13. Ruiz-Argüelles GJ, Apreza-Molina MG, Alemán-Hoey DD, et al. Outpatient supportive therapy after induction to remission therapy in adult acute myelogenous leukaemia (AML) is feasible: a multicentre study. Eur J Haematol 1995;54:18-20.

14. Eisele L, Günther F, Ebeling $P$, et al. Outpatient management of acute myeloid leukemia after intensive consolidation chemotherapy is feasible and reduces hospital treatment costs. Onkologie 2010;33:658-664.

15. Jencks SF, Williams MV, Coleman EA. Rehospitalizations among patients in the Medicare fee-for-service program. N Engl J Med 2009;360: 1418-1428.

16. Merz TM, Schär $P$, Bühlmann M, et al. Resource use and outcome in critically ill patients with hematological malignancy: a retrospective cohort study. Crit Care 2008;12:R75

17. Halpern AB, Culakova E, Walter RB, et al. Association of risk factors, mor tality, and care costs of adults with acute myeloid leukemia with admission to the intensive care unit. JAMA Oncol 2017:3:374-381.

18. Walter RB, Taylor LR, Gardner KM, et al. Outpatient management following intensive induction or salvage chemotherapy for acute myeloid leukemia. Clin Adv Hematol Oncol 2013;11:571-577.

19. Halpern AB, Walter RB. Practice patterns and outcomes for adults with acute myeloid leukemia receiving care in community vs academic settings. Hematology (Am Soc Hematol Educ Program) 2020;2020:129-134 
Supplemental online content for:

\section{Financial Implications of Early Hospital Discharge After AML-Like Induction Chemotherapy: A 4-Year Retrospective Analysis}

Nathan J. Moore, MD; Megan Othus, PhD; Anna B. Halpern, MD; Nicholas P. Howard, BS; Linyi Tang, MS; Kyle E. Bastys, MPH; Mary-Elizabeth M. Percival, MD, MS; Paul C. Hendrie, MD, PhD; Garrett A. Hartley, MBA, $\mathrm{MPH}$; Verna L. Welch, PhD, MPH; Elihu H. Estey, MD; and Roland B. Walter, MD, PhD, MS

J Natl Compr Canc Netw 2021, doi: 10.6004/jnccn.2020.7683

eTable 1: Characteristics of Patients With Blood Count Recovery

eTable 2: Safety and Resource Utilization of Patients With Blood Count Recovery

eTable 3: Charges per Day for Patients With Blood Count Recovery

eTable 4: Characteristics of Medically Matched Patients

eTable 5: Safety and Resource Utilization of Medically Matched Patients

eTable 6: Characteristics of Medically Matched Patients With Blood Count Recovery

eTable 7: Safety and Resource Utilization of Medically Matched With Blood Count Recovery

eTable 8: Charges per Day for Medically Matched Patients With Blood Count Recovery 


\section{eTable 1. Characteristics of EHD and Inpatient Control Patients With Blood Count Recovery}

Parameter

Total, N

Patient demographics

Age, mean (range), y

Sex

Female

Male

Travel time to outpatient clinic, mean (range), min

Insurance type

Medicare

Medicaid

Private

Other

isease characteristics

Disease

\begin{tabular}{lc}
\hline AML & $124(8)$ \\
\hline MDS & $29(19)$ \\
\hline Secondary disease & $46(30)$ \\
\hline Cytogenetic risk & $20(1$ \\
\hline Favorable & $47(3$ \\
\hline Intermediate-1 & $30(2)$ \\
\hline Intermediate-2 & $43(3)$ \\
\hline Adverse &
\end{tabular}

Chemotherapy administered

HiDAC-containing regimens

$7+3$ ( \pm additional drug)

Cytarabine/Decitabine ${ }^{a}$

Clinical/Laboratory findings at baseline

Performance status

0-1

2-4

Creatinine, $\mathrm{mg} / \mathrm{dL}$

Total bilirubin, $\mathrm{mg} / \mathrm{dL}$

Albumin, g/dL

WBC count, thousand/microL

$\%$ peripheral blood blasts

TRM score
EHD Cohort

n (\%)

153

n (\%)

41

$58(25-80)$

.15

.48

21 (51)

20 (49)

$63(4-155)$

$<.001$

.40

20 (49)

6 (15)

13 (32)

2 (5)

$\begin{array}{lc}6(37) & 20(49) \\ 8(12) & 6(15) \\ 6(43) & 13(32) \\ 3(8) & 2(5)\end{array}$

$P$ Value

37 (90)

4 (10)

7 (17)

.12

.016

11 (30)

16 (43)

2 (5)

8 (22)

.014

36 (88)

3 (7)

2 (5) 


\begin{tabular}{|c|c|c|c|}
\hline Parameter & $\begin{array}{c}\text { EHD Cohort } \\
\text { n (\%) }\end{array}$ & $\begin{array}{c}\text { Inpatient Cohort } \\
\mathrm{n}(\%)\end{array}$ & $P$ Value \\
\hline \multicolumn{4}{|c|}{ Clinical/Laboratory findings postchemotherapy } \\
\hline Performance status & & & $<.001$ \\
\hline $0-1$ & $137(90)$ & $18(44)$ & \\
\hline $2-4$ & $16(10)$ & $23(56)$ & \\
\hline Creatinine, $\mathrm{mg} / \mathrm{dL}$ & $0.71(0.32-2.65)$ & $0.72(0.25-2.71)$ & .37 \\
\hline Total bilirubin, $\mathrm{mg} / \mathrm{dL}$ & $0.98(0.2-5.1)$ & $1.12(0.3-2.6)$ & .049 \\
\hline Albumin, $\mathrm{g} / \mathrm{dL}$ & $3.56(2.1-5)$ & $3.04(1.9-3.9)$ & $<.001$ \\
\hline WBC count, thousand/microL & $0.89(0-19.79)$ & $0.68(0-14.73)$ & .14 \\
\hline \% peripheral blood blasts & $1.35(0-46)$ & $0.73(0-30)$ & .19 \\
\hline TRM score & $5.77(0.34-28.12)$ & $14.21(1.23-77.63)$ & $<.001$ \\
\hline Treatment response & & & .36 \\
\hline No $C R / C R i$ & $12(8)$ & $5(12)$ & \\
\hline $\mathrm{CR}$ or $\mathrm{CRi}$ & $141(92)$ & $36(88)$ & \\
\hline
\end{tabular}

Abbreviations: $\mathrm{AML}$, acute myeloid leukemia; $\mathrm{CR}$, complete remission; $\mathrm{CRi}$, complete remission with incomplete hematologic recovery; EHD, early hospital discharge; HiDAC, high-dose cytarabine; MDS, myelodysplastic syndromes; TRM, treatment-related mortality; WBC, white blood cell.

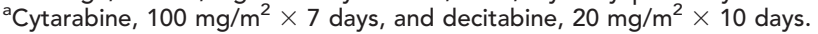




\section{eTable 2. Safety and Resource Utilization of EHD and Inpatient Control Patients With Blood Count} Recovery

\begin{tabular}{|c|c|c|c|}
\hline Parameter & $\begin{array}{l}\text { EHD Cohort } \\
\text { Mean (Range) }\end{array}$ & $\begin{array}{c}\text { Inpatient Cohort } \\
\text { Mean (Range) }\end{array}$ & $P$ Value \\
\hline Total, N & 153 & 41 & \\
\hline Days on study & $22.81(14-41)$ & $18.56(5-34)$ & $<.001$ \\
\hline Days as inpatient & $6.10(0-25)$ & $18.56(5-34)$ & $<.001$ \\
\hline Days as outpatient & $16.71(3-38)$ & - & - \\
\hline Time spent as outpatient, $\%$ & $72.45(11-100)$ & - & - \\
\hline Number of readmissions & $1.08(0-3)$ & - & - \\
\hline Days in ICU & $0.14(0-8)$ & $0.59(0-11)$ & .067 \\
\hline Study days spent in ICU, \% & $0.70(0-38.10)$ & $3.09(0-57.89)$ & .067 \\
\hline \multicolumn{4}{|l|}{ Early death, n (\%) } \\
\hline No early death & $151(99)$ & $40(98)$ & .51 \\
\hline Died $\leq 30$ days after start of study & $2(1)$ & $1(2)$ & - \\
\hline Physician visits per outpatient study day & $0.06(0-0.33)$ & - & - \\
\hline RN/APP visits per outpatient study day & $0.10(0-0.50)$ & - & - \\
\hline Outpatient laboratory visits per outpatient study day & $0.44(0-1.00)$ & 一 & - \\
\hline ED visits per study day & $0.04(0-0.16)$ & & \\
\hline Study days on IV antimicrobials, \% & $36.84(0-100)$ & $52.22(0-100)$ & .01 \\
\hline \multicolumn{4}{|l|}{ RBC transfusions per study day } \\
\hline Total & $0.27(0.04-0.80)$ & $0.40(0.13-0.92)$ & $<.001$ \\
\hline Inpatient & $0.61(0-2.33)$ & $0.40(0.13-0.92)$ & $<.001$ \\
\hline Outpatient & $0.15(0-0.65)$ & - & - \\
\hline \multicolumn{4}{|l|}{ Platelet transfusions per study day } \\
\hline Total & $0.24(0.04-1.06)$ & $0.41(0.10-1.20)$ & $<.001$ \\
\hline Inpatient & $0.38(0-2.33)$ & $0.41(0.10-1.20)$ & .19 \\
\hline Outpatient & $0.19(0-1.00)$ & 一 & 一 \\
\hline
\end{tabular}

Abbreviations: APP, advanced practice provider; ED, emergency department; EHD, early hospital discharge; ICU, intensive care unit; IV, intravenous; $\mathrm{RBC}$, red blood cell; RN, registered nurse 
eTable 3. Charges per Day for EHD and Inpatient Control Patients With Blood Count Recovery

\begin{tabular}{|c|c|c|c|}
\hline Charge Category & $\begin{array}{c}\text { EHD Cohort } \\
\text { Charges per Day (Range), USD }\end{array}$ & $\begin{array}{c}\text { Inpatient Cohort } \\
\text { Charges per Day (Range), USD }\end{array}$ & $P$ Value \\
\hline \multicolumn{4}{|l|}{ All categories } \\
\hline Combined & $3,826(905-9,954)$ & $8,404(4,596-26,320)$ & $<.001$ \\
\hline Inpatient only & $8,119(4,828-16,068)$ & $8,404(4,596-26,320)$ & .59 \\
\hline \multicolumn{4}{|l|}{ Facility/Provider } \\
\hline Inpatient only & $3,419(1,693-6,410)$ & $3,592(2,806-9,907)$ & .14 \\
\hline \multicolumn{4}{|c|}{ Emergency department } \\
\hline Combined & $103(0-480)$ & $0(0-0)$ & $<.001$ \\
\hline \multicolumn{4}{|l|}{ Transfusion } \\
\hline Combined & $1,111(225-3,780)$ & $1,875(628-7,933)$ & $<.001$ \\
\hline Inpatient only & $993(307-2,897)$ & $916(338-3,031)$ & .15 \\
\hline \multicolumn{4}{|l|}{ Imaging } \\
\hline Combined & $172(0-852)$ & $333(0-1,708)$ & .038 \\
\hline Inpatient only & $502(0-2,904)$ & $333(0-1,708)$ & .011 \\
\hline \multicolumn{4}{|l|}{ Pharmacy } \\
\hline Combined & $497(10-1,797)$ & $1,538(130-3,330)$ & $<.001$ \\
\hline Inpatient only & $1,531(265-3,500)$ & $1,538(130-3,330)$ & .42 \\
\hline \multicolumn{4}{|l|}{ Miscellaneous } \\
\hline Combined & $72(0-598)$ & $150(0-991)$ & .43 \\
\hline
\end{tabular}

Abbreviation: EHD, early hospital discharge. 


\section{eTable 4. Characteristics of Medically Matched EHD and Inpatient Control Patients}

\begin{tabular}{|c|c|c|c|}
\hline Parameter & $\begin{array}{c}\text { EHD Cohort } \\
\mathrm{n}(\%)\end{array}$ & $\begin{array}{c}\text { Inpatient Cohort } \\
\mathrm{n}(\%)\end{array}$ & $P$ Value \\
\hline Total, N & 152 & 49 & \\
\hline \multicolumn{4}{|l|}{ Patient demographics } \\
\hline Age, mean (range), y & $56.31(18-83)$ & $54.92(24-90)$ & .65 \\
\hline Sex & & & .19 \\
\hline Female & $60(40)$ & $25(51)$ & \\
\hline Male & $90(60)$ & $24(49)$ & \\
\hline Travel time to outpatient clinic, mean (range), min & $17.27(1-58)$ & $53.32(2-155)$ & $<.001$ \\
\hline Insurance type & & & .11 \\
\hline Medicare & $57(38)$ & $22(45)$ & \\
\hline Medicaid & $18(12)$ & & $11(22)$ \\
\hline Private & $62(41)$ & & $12(24)$ \\
\hline Other & $13(9)$ & & $4(8)$ \\
\hline Disease characteristics & & & .026 \\
\hline Disease & $122(80)$ & $46(94)$ & \\
\hline AML & $30(20)$ & $3(6)$ & \\
\hline MDS & $49(33)$ & $17(35)$ & \\
\hline Secondary disease & & & .86 \\
\hline Cytogenetic risk & & & .43 \\
\hline Favorable & $16(12)$ & $9(20)$ & \\
\hline Intermediate-1 & $44(32)$ & $16(36)$ & \\
\hline Intermediate-2 & $31(23)$ & $7(16)$ & \\
\hline Adverse & $45(33)$ & $13(29)$ & \\
\hline Chemotherapy administered $^{\mathrm{a}}$ & & & .40 \\
\hline HiDAC-containing regimens & $142(95)$ & $45(92)$ & \\
\hline $7+3$ ( \pm additional drug) & $6(4)$ & $2(4)$ & \\
\hline Cytarabine/Decitabine ${ }^{a}$ & $2(1)$ & $2(4)$ & \\
\hline \multicolumn{4}{|l|}{ Clinical/Laboratory findings at baseline } \\
\hline Performance status & & & 1.00 \\
\hline $0-1$ & $144(96)$ & $47(96)$ & \\
\hline $2-4$ & $6(4)$ & $2(4)$ & \\
\hline Creatinine, $\mathrm{mg} / \mathrm{dL}$ & $0.91(0.48-4.36)$ & $0.9(0.47-1.48)$ & .51 \\
\hline Total bilirubin, mg/dL & $0.79(0.2-2.9)$ & $0.67(0.3-1.6)$ & .23 \\
\hline Albumin, g/dL & $3.89(2.5-5.0)$ & $3.7(2.5-4.7)$ & .0062 \\
\hline WBC count, thousand/microL & $17.47(0.39-261.48)$ & $34.33(0.62-247.93)$ & .0052 \\
\hline$\%$ peripheral blood blasts & $21.57(0-97)$ & $35.2(0-97)$ & .0022 \\
\hline TRM score & $3.32(0-16.80)$ & $4.58(0-32.15)$ & .41 \\
\hline \multicolumn{4}{|l|}{ Clinical/Laboratory findings postchemotherapy } \\
\hline Creatinine, $\mathrm{mg} / \mathrm{dL}$ & $0.73(0.35-2.65)$ & $0.72(0.40-1.41)$ & .54 \\
\hline Total bilirubin, $\mathrm{mg} / \mathrm{dL}$ & $0.95(0.2-3.0)$ & $0.8(0.3-2.6)$ & .20 \\
\hline Albumin, g/dL & $3.55(2.1-5.0)$ & $3.37(2.4-4.6)$ & .023 \\
\hline WBC count, thousand/microL & $1.14(0-37.20)$ & $0.75(0-9.38)$ & .41 \\
\hline$\%$ peripheral blood blasts & $1.43(0-46)$ & $0.84(0-38)$ & .30 \\
\hline TRM score & $5.25(0.34-13.56)$ & $5.55(0.11-16.26)$ & .75 \\
\hline
\end{tabular}




\begin{tabular}{|c|c|c|c|}
\hline Parameter & $\begin{array}{c}\text { EHD Cohort } \\
\mathrm{n}(\%)\end{array}$ & $\begin{array}{c}\text { Inpatient Cohort } \\
\mathrm{n}(\%)\end{array}$ & $P$ Value \\
\hline Treatment response & & & .004 \\
\hline No CR/CRi & $24(16)$ & $18(37)$ & \\
\hline $\mathrm{CR} / \mathrm{CRi}$ & $128(84)$ & $31(63)$ & \\
\hline Off-study reason & & & $<.001$ \\
\hline Blood count recovery & $130(87)$ & $15(31)$ & \\
\hline Day 42 & $8(5)$ & $1(2)$ & \\
\hline Death & $4(3)$ & $0(0)$ & \\
\hline Hospital discharge & $0(0)$ & $31(63)$ & \\
\hline New AML therapy & $6(4)$ & $2(4)$ & \\
\hline Transfer of care to outside facility & $2(1)$ & $0(0)$ & \\
\hline
\end{tabular}

Abbreviations: AML, acute myeloid leukemia; EHD, early hospital discharge; $C R$, complete remission; $C R i$, complete remission with incomplete hematologic recovery; HiDAC, high-dose cytarabine; MDS, myelodysplastic syndromes; TRM, treatment-related mortality; WBC, white blood cell.

${ }^{a}$ Cytarabine, $100 \mathrm{mg} / \mathrm{m}^{2} \times 7$ days, and decitabine, $20 \mathrm{mg} / \mathrm{m}^{2} \times 10$ days. 


\section{eTable 5. Safety and Resource Utilization of Medically Matched EHD and Inpatient Control Patients}

\begin{tabular}{|c|c|c|c|}
\hline Parameter & $\begin{array}{l}\text { EHD Cohort } \\
\text { Mean (Range) }\end{array}$ & $\begin{array}{l}\text { Inpatient Cohort } \\
\text { Mean (Range) }\end{array}$ & $P$ Value \\
\hline Total, N & 152 & 49 & \\
\hline Days on study & $24.00(6-42)$ & $15.98(3-42)$ & $<.001$ \\
\hline Days as inpatient & $6.24(0-25)$ & $15.98(3-42)$ & $<.001$ \\
\hline Days as outpatient & $17.76(1-42)$ & - & - \\
\hline Time spent as outpatient, $\%$ & $72.38(11-100)$ & - & - \\
\hline Number of readmissions & $1.10(0-3)$ & - & - \\
\hline Days in ICU & $0.25(0-16)$ & $0(0-0)$ & .08 \\
\hline Study days spent in ICU, \% & $1.01(0-38.1)$ & $0(0-0)$ & .08 \\
\hline Early death, n (\%) & & & .34 \\
\hline No early death & $147(97)$ & $49(100)$ & \\
\hline Died $\leq 30$ days after start of study & $5(3)$ & $0(0)$ & \\
\hline Physician visits per outpatient study day & $0.06(0-0.33)$ & - & - \\
\hline RN/APP visits per outpatient study day & $0.10(0-0.50)$ & - & - \\
\hline Outpatient laboratory visits per outpatient study day & $0.45(0-1.00)$ & - & - \\
\hline ED visits per study day & $0.04(0-0.17)$ & - & - \\
\hline Study days on IV antimicrobials, \% & $37.05(0-100)$ & $40.90(0-100)$ & .71 \\
\hline \multicolumn{4}{|l|}{ RBC transfusions per study day } \\
\hline Total & $0.27(0.04-0.80)$ & $0.40(0-1.00)$ & $<.001$ \\
\hline Inpatient & $0.60(0-1.50)$ & $0.40(0-1.00)$ & $<.001$ \\
\hline Outpatient & $0.16(0-0.75)$ & - & - \\
\hline \multicolumn{4}{|l|}{ Platelet transfusions per study day } \\
\hline Total & $0.24(0.04-1.06)$ & $0.4(0.09-1.38)$ & $<.001$ \\
\hline Inpatient & $0.38(0-1.27)$ & $0.4(0.09-1.38)$ & 1.00 \\
\hline Outpatient & $0.19(0-1.00)$ & - & 一 \\
\hline
\end{tabular}

Abbreviations: APP, advanced practice provider; ED, emergency department; EHD, early hospital discharge; ICU, intensive care unit; IV, intravenous; $\mathrm{RBC}$, red blood cell; $\mathrm{RN}$, registered nurse. 


\section{eTable 6. Characteristics of Medically Matched EHD and Inpatient Control Patients With Blood Count} Recovery

\begin{tabular}{|c|c|c|c|}
\hline Parameter & $\begin{array}{l}\text { EHD Cohort } \\
\text { n (\%) }\end{array}$ & $\begin{array}{c}\text { Inpatient Cohort } \\
\mathrm{n}(\%)\end{array}$ & $P$ Value \\
\hline Total, N & 130 & 15 & \\
\hline \multicolumn{4}{|l|}{ Patient demographics } \\
\hline Age, mean (range), y & $55(18-79)$ & $51(25-73)$ & .70 \\
\hline Sex & & & .18 \\
\hline Female & $54(42)$ & $9(60)$ & \\
\hline Travel time to outpatient clinic, mean (range), min & $17(1-58)$ & $89(28-155)$ & $<.001$ \\
\hline Insurance type & & & .37 \\
\hline Medicare & $47(36)$ & $7(47)$ & \\
\hline Medicaid & $14(11)$ & $3(20)$ & \\
\hline AML & $104(80)$ & $14(93)$ & \\
\hline MDS & $26(20)$ & $1(7)$ & \\
\hline Secondary disease & $40(31)$ & $3(20)$ & .55 \\
\hline Cytogenetic risk & & & .021 \\
\hline Favorable & $16(14)$ & $5(38)$ & \\
\hline Intermediate-1 & $39(33)$ & $6(46)$ & \\
\hline Intermediate-2 & $26(22)$ & $0(0)$ & \\
\hline Adverse & $37(31)$ & $2(15)$ & \\
\hline Chemotherapy administered & & & .12 \\
\hline Creatinine, mg/dL & $0.90(0.48-4.36)$ & $0.78(0.47-1.25)$ & .86 \\
\hline Total bilirubin, $\mathrm{mg} / \mathrm{dL}$ & $0.78(0.2-2.9)$ & $0.77(0.3-1.6)$ & .063 \\
\hline Albumin, g/dL & $3.9(2.5-5.0)$ & $3.7(2.9-4.2)$ & .022 \\
\hline WBC count, thousand/microL & $16.58(0.39-261.48)$ & $28.01(1.83-138.44)$ & .022 \\
\hline$\%$ peripheral blood blasts & $21.19(0-97)$ & $34.27(0-93)$ & .99 \\
\hline TRM score & $3(0-16.80)$ & $3.14(0.3-10.96)$ & .54 \\
\hline
\end{tabular}




\section{eTable 6. Characteristics of Medically Matched EHD and Inpatient Control Patients With Blood Count} Recovery (cont.)

\begin{tabular}{|c|c|c|c|}
\hline Parameter & $\begin{array}{l}\text { EHD Cohort } \\
n(\%)\end{array}$ & $\begin{array}{c}\text { Inpatient Cohort } \\
\mathrm{n}(\%)\end{array}$ & $P$ Value \\
\hline \multicolumn{4}{|c|}{ Clinical/Laboratory findings postchemotherapy } \\
\hline Creatinine, mg/dL & $0.72(0.32-2.65)$ & $0.63(0.40-1.00)$ & .16 \\
\hline Total bilirubin, $\mathrm{mg} / \mathrm{dL}$ & $0.94(0.2-3.0)$ & $1.00(0.3-2.6)$ & .64 \\
\hline Albumin, g/dL & $3.56(2.1-5.0)$ & $3.21(2.7-3.8)$ & .0035 \\
\hline WBC count, thousand/microL & $0.83(0-19.79)$ & $0.39(0-2.19)$ & .56 \\
\hline$\%$ peripheral blood blasts & $1.41(0-46)$ & $0(0-0)$ & .27 \\
\hline TRM score & $4.85(0.34-13.56)$ & $4.82(1.23-9.26)$ & 1.00 \\
\hline Treatment response & & & .28 \\
\hline No CR/CRi & $8(6)$ & $2(13)$ & \\
\hline CR or CRi & $122(94)$ & $13(87)$ & \\
\hline
\end{tabular}

Abbreviations: $\mathrm{AML}$, acute myeloid leukemia; $\mathrm{CR}$, complete remission; $\mathrm{CRi}$, complete remission with incomplete hematologic recovery; EHD, early hospital discharge; HiDAC, high-dose cytarabine; MDS, myelodysplastic syndromes; TRM, treatment-related mortality; WBC, white blood cell. 
eTable 7. Safety and Resource Utilization of Medically Matched EHD and Inpatient Control Patients With Blood Count Recovery

\begin{tabular}{|c|c|c|c|}
\hline Parameter & $\begin{array}{l}\text { EHD Cohort } \\
\text { Mean (Range) }\end{array}$ & $\begin{array}{l}\text { Inpatient Cohort } \\
\text { Mean (Range) }\end{array}$ & $P$ Value \\
\hline Total, N & 130 & 15 & \\
\hline Days as inpatient & $5.91(0-25)$ & $18.2(5-28)$ & $<.001$ \\
\hline Days as outpatient & $16.72(3-38)$ & - & - \\
\hline Days in ICU & $0.15(0-8)$ & $0(0-0)$ & .44 \\
\hline Study days spent in ICU, \% & $0.75(0-38.1)$ & $0(0-0)$ & .44 \\
\hline \multicolumn{4}{|l|}{ Early death, n (\%) } \\
\hline No early death & $128(98)$ & $15(100)$ & 1.00 \\
\hline Outpatient laboratory visits per outpatient study day & $0.44(0-1.00)$ & - & - \\
\hline ED visits per study day & $0.04(0-0.16)$ & & \\
\hline Study days on IV antimicrobials, \% & $36.76(0-100)$ & $40.13(0-100)$ & .69 \\
\hline \multicolumn{4}{|l|}{ RBC transfusions per study day } \\
\hline Total & $0.27(0.04-0.80)$ & $0.37(0.13-0.83)$ & .026 \\
\hline Inpatient & $0.60(0-1.50)$ & $0.37(0.13-0.83)$ & $<.001$ \\
\hline Outpatient & $0.15(0-0.65)$ & - & - \\
\hline \multicolumn{4}{|l|}{ Platelet transfusions per study day } \\
\hline Total & $0.23(0.04-1.06)$ & $0.23(0.10-0.56)$ & .94 \\
\hline
\end{tabular}

Abbreviations: APP, advanced practice provider; ED, emergency department; EHD, early hospital discharge; ICU, intensive care unit; IV, intravenous; $\mathrm{RBC}$, red blood cell; RN, registered nurse 


\section{eTable 8. Charges per Day for Medically Matched EHD Versus Inpatient Control Patients With Blood} Count Recovery

\begin{tabular}{|c|c|c|c|}
\hline Charge Category & $\begin{array}{c}\text { EHD Cohort }(n=130) \\
\text { Charges per Day (Range), USD }\end{array}$ & $\begin{array}{c}\text { Inpatient Cohort ( } n=15) \\
\text { Charges per Day (Range), USD }\end{array}$ & $P$ Value \\
\hline Total, N & 130 & 15 & \\
\hline \multicolumn{4}{|l|}{ All categories } \\
\hline Combined & $3,792(905-9,954)$ & $6,429(4,596-8,342)$ & $<.001$ \\
\hline Inpatient only & $8,076(4,828-16,068)$ & $6,429(4,596-8,342)$ & $<.001$ \\
\hline \multicolumn{4}{|l|}{ Facility/Provider } \\
\hline Combined & $1,200(104-4,060)$ & $3,331(3,034-3,758)$ & $<.001$ \\
\hline Inpatient only & $3,417(1,693-6,410)$ & $3,331(3,034-3,758)$ & .81 \\
\hline \multicolumn{4}{|c|}{ Emergency department } \\
\hline Combined & $103(0-480)$ & $0(0-0)$ & $<.001$ \\
\hline \multicolumn{4}{|l|}{ Transfusion } \\
\hline Combined & $1,091(225-3,780)$ & $1,216(628-2,181)$ & .23 \\
\hline Inpatient only & $1,604(306-3,768)$ & $1,216(628-2,181)$ & .031 \\
\hline \multicolumn{4}{|c|}{ Laboratory/Pathology } \\
\hline Combined & $694(87-2,398)$ & $721(353-1,195)$ & .52 \\
\hline Inpatient only & $1,001(307-2,897)$ & $721(353-1,195)$ & .018 \\
\hline \multicolumn{4}{|l|}{ Imaging } \\
\hline Combined & $167(0-852)$ & $79(0-335)$ & .11 \\
\hline Inpatient only & $526(0-2,904)$ & $79(0-335)$ & $<.001$ \\
\hline \multicolumn{4}{|l|}{ Pharmacy } \\
\hline Combined & $494(10-1,797)$ & $1,018(130-1,611)$ & $<.001$ \\
\hline Inpatient only & $1,538(265-3,500)$ & $1,018(130-1,611)$ & $<.001$ \\
\hline \multicolumn{4}{|l|}{ Miscellaneous } \\
\hline Combined & $71(0-598)$ & $65(0-623)$ & .0023 \\
\hline Inpatient only & $75(0-1,217)$ & $65(0-623)$ & .58 \\
\hline
\end{tabular}

Abbreviation: EHD, early hospital discharge. 